\title{
Connections Before Curriculum: The Role of Social Presence During COVID-19 Emergency Remote Learning for Students
}

\author{
Suzanne Ensmann \\ Aimee Whiteside \\ Lina Gomez-Vasquez \\ Ronda Sturgill \\ University of Tampa
}

\begin{abstract}
This study examined the student experience $(n=507)$ during emergency remote learning at a medium-sized private southeastern university during the COVID-19 pandemic, leveraging the Social Presence Model (SPM) as a guiding framework. Tensions were high at this critical time as students were stressed with financial burdens, supply shortages, overlapping work and educational schedules, and shared technological resources and physical spaces. Therefore, this study helps educators better understand students' emotional needs and experiences during the March 2020 lockdown transition to remote learning. Specifically, examining the student experience in a time of crisis offers critical lessons about the importance of connectedness, online readiness, cultivating relationships, adaptability during transitions, and class interaction. The data revealed the depth of anxiety felt by students and suggests the need for increased empathy, communication, interaction, and flexibility from their instructor and course community to proceed with academic coursework, particularly for first-year college students. The findings elevate the importance of social presence as a literacy for learning in any modality, underscore the need to support the mental health of our students, and stress the urgency for online and remote learning readiness for current and future public emergencies.
\end{abstract}

Keywords: Social presence, connectedness, COVID-19, online learning, remote learning, online readiness

Ensmann, S., Whiteside, A., Gomez-Vasquez, L., \& Sturgill, R. (2021). Connections before curriculum: The role of social presence during COVID-19 emergency remote learning for students. Online Learning, 25(3), 36-56. doi: 10.24059/olj.v25i3.2868 
As the pandemic's first wave surged across the globe in March 2020, instructors dove headfirst into the previously uncharted waters of remote emergency learning during the COVID19 lockdown. Millions of educators learned to quickly adapt their course materials and teaching styles to different modalities in its wake. Students who previously navigated their on-campus courses on autopilot suddenly became online learning project managers as they organized their new schedules and adjusted to each instructor's online and remote course adaptations as well as their new learning spaces.

As a result of the tidal wave of change, an understandable lack of online readiness resulted in diminished social presence in learning environments (Cutri et al., 2020). This deficiency stems from faculty getting courses ready for remote learning with short notice. Cutri and her colleagues (2020) noted,

Faculty, including teacher educators, were asked to transition, create, and implement online teaching due to university closures with no choice but to teach online even if they did not feel properly prepared to do so, or formerly had little interest in online teaching (p. 523).

Moreover, technology laggards got caught in the undertow of a completely new paradigm of teaching and learning. With little or no professional development, they struggled to keep their heads above the water (Ensmann et al., 2021; Whiteside, 2017).

Faculty members' lack of readiness had a domino effect on students who already lacked online readiness (Cutri et al. 2020; Tang et al. 2021). Additionally, many students faced challenges, including not having their books, quickly moving away from campus, and managing courses taught in synchronous and asynchronous formats. Family stress and tensions were high and even compounded for international students. Faculty navigated the best way while underestimating the importance of connectedness for students, the emotional impact of COVID, and the overall importance of social presence at the time. Emerging studies on the 2020-21 student experience showcase numerous constraints, large cultural disparities, mixed emotions, and varied scholastic results (Nguyen et al., 2021).

Building from this foundation, this study is part of a larger study that explores the holistic student experience during COVID-19 emergency remote learning. The purpose of this specific study was to explore the student experience of needing connections and support in a time of considerable disconnection and confusion in higher education. It employs the Social Presence Model (SPM) as a framework because of its unique positioning as a heuristic developed to explore social presence in both connectedness and experience. The authors begin with a summary of the literature on COVID-19 remote learning and social presence. It presents the social presence methodology, methods, and findings, and it ends with the study's implications.

\section{Research Questions}

This study focused on the following research questions:

1. What was the student experience in the transition to remote learning?

2. How can we better understand the experience through the lens of the social presence model?

Focusing on the results related to SPM from the students' perspective, this article provides the first in a series of data analysis reports that examine the depth of the different categories of student and faculty data collected. 


\section{Literature Review}

This study fills a gap by helping us to better understand students' emotional needs and experiences during the March 2020 lockdown transition. This section situates the study within the social presence and COVID-19 remote learning consideration.

\section{Social Presence}

The importance of connections, interactions, and the socio-emotional aspects of learning are often underrated and overlooked. As humans, we crave these connections, and, in learning environments, we need them even more. Lave and Wenger (1991) and Wenger (1998) addressed the importance of relationships, networking, and connections for meaning-making within a discipline. To thrive with a learning community, students need to "engage directly in activities, conversations, reflections, and other forms of personal participation" while simultaneously interacting with the material and learning "artifacts" (Wenger, 2000, p. 225). Learning is a powerful negotiation of meaning among participants in an "informal and dynamic social structure" (p. 226). Wenger viewed learning as a "process of realignment between socially defined competence and personal experience," which involves a careful toggling of "identification and dis-identification" within the learning community (p. 226-227). Zhao and Kuh (2004) drew from their research to address how learning communities involve the social construction of information for "learning [that] is deeper, more personally relevant, and becomes a part of who the student is, not just something the student has" (p. 117).

Not only is learning, at its core, a social activity within a learning community, but it is also a deeply personal process of trust and relationship building. Conrad and Donaldson (2012) suggested, in their phases of engagement framework, that relationship building is the first phase of engaging the online learner, and it is not to be skipped. They suggested that social negotiation through icebreakers and social interaction and establishing community norms and orientation allows instructors to leverage those connections in the academic content in the subsequent weeks of the course.

As Wenger (2000) suggested, "Learning is a social becoming" (p. 227). This social becoming forms the basis of social presence, the framework for this study. Social presence is a concept dating back to the mid-1960s, long before the advent of online learning. Originating from the research of social psychologists Short, Williams, and Christy (1976), social presence was considered the lack of the "real person" in the teleconferencing experience. These experts described social presence as the "degree of salience of the other person in the interaction and the consequent salience of the interpersonal relationships" in what became known as Social Presence Theory (Short et al., p. 72-73).

Then, as technology gained prominence in K12 and higher education in the early 1990s, educators began exploring various advances in instructional technology, including interactive television (ITV), video, and blended and online learning. At this time, the concept of social presence became increasingly more popular and nuanced. Gunawardena and Zittle (1997) defined social presence as "the degree to which a person is perceived as 'real' in mediated communication" (p. 9). Swan and Shui (2005) suggested the need for "explicit training for students in the importance of social presence, ways of presenting themselves online, and the nature of online discussion might help particular students better adapt to the medium" (p. 131).

Whiteside, Garrett Dikkers, and Swan (2017) classified social presence into multiple perspectives. The first perspective derives from Short et al.'s, (1976) Social Presence Theory and focuses on the role of technology in facilitating social presence. The second perspective suggests that social presence is learner-centered. The central framework for the first two perspectives is 
the Community of Inquiry framework, a framework centered on three components: social presence, teacher presence, and cognitive presence. (Garrison, 2007; Garrison, 2018; Garrison et al., 2010; Swan et al., 2009).

The third and final perspective focuses on Whiteside's $(2007 ; 2011 ; 2015)$ Social

Presence Model, the framework for this study. This model views social presence as the culmination of the whole social learning system, including affect/emotion, interaction level, community building, instructor involvement, and the learners' knowledge and experience (Garrett Dikkers, Whiteside, \& Tapp, 2017). Today, social presence research draws from a wide range of disciplinary research, frameworks, and philosophical ideologies.

\section{COVID-19 Remote Learning Considerations}

Social presence becomes even more fundamental when considering the complexities involved in understanding the skills and support students need during the 2020 COVID-19 emergency remote learning. For example, students often cannot anticipate or articulate what they need before they need it, or they are unfamiliar with the terminology, forethought, and planning involved in learning across modalities, e.g., synchronous, and asynchronous. Martin and colleagues offered a body of literature dedicated to student online learning readiness (Martin \& Bollinger, 2018; Martin \& Parker, 2014; Martin et al., 2020). These experts contended, "Students should be encouraged to reflect on their attributes as an online learner, their time management, communication, and technical skills. It is crucial for students to be prepared in all these four areas" (Martin et al., 2020, p. 54). Students' self-reflections and the corresponding support systems become even more critical during an emergency pandemic to avoid disillusionment, disengagement, and attrition. For example, Bird et al. at the Annenberg Institute for School Reform (2020) noted a $6.7 \%$ decrease in course completion at one large eastern university due to the pandemic. Furthermore, to reduce student anxiety about the online learning experience, preparedness for a course through online learning orientations can improve student satisfaction (Abdous, 2019).

To sustain retention levels and engagement as well as help better prepare students for remote and online learning, Rapanta et al. (2020) suggested that the pandemic shift requires reconsideration of Anderson et al.'s (2001) tri-fold focus on cognitive, social, and teaching presence, taking into "consideration students' preparedness to participate in the online learning experience" (p. 939). Likewise, Conklin and Garrett Dikkers (2021) found in their study that during the COVID 19 pandemic, students felt more connected when instructors leveraged video, used a conversational tone, incorporated empathy into messaging, and provided timely feedback. While students may never be truly prepared for something like the March 2020 shift to emergency remote learning, faculty development programs and online academic communities can help faculty understand students' socio-emotional needs better as they move into learning in different modalities. Additionally, Chiu (2021) contended that "a positive attitude and enthusiasm online to foster relatedness can help positive teacher-student relationships and better emotionally engage students in learning" (p.13). Specifically, Chiu suggests using emojis messages and offering "feedback...as warm and friendly audio messages" (p.13). Further, Nguyen et al. (2021) recommended social presence in remote learning in a study with almost 5,000 participants. The isolation from the pandemic heightens the need for social presence in online learning. 
Although Chiu suggested that students require an increase of social presence during crises, such as the COVID-19 pandemic, Rutherford et al. (2021) observe that many faculty members became considerably less socially present during this time. Rutherford et al. (2021) noted that instructors tended to shift from "highly-supportive F2F profiles to less supportive profiles," which "emphasizes the need for universities to support instructors transitioning to online learning" (p. 107). It is also likely that faculty had to attend to their own families, assisting with their own kids' e-learning, struggle to find working spaces, technology, and equipment, and search for professional development opportunities to advance their upcoming lessons. Therefore, the professional-personal tensions made it difficult for faculty to model social presence and be socially present for their students at this critical time.

\section{Guiding Framework}

The researchers selected social presence as the lens for this study because of its unique focus on both experience and connectedness. Thus, the guiding framework for this study is the Social Presence Model (SPM), which consists of five essential overlapping elements: Affective Association, Community Cohesion, Instructor Involvement, Interaction Intensity, and Knowledge and Experience. We define social presence as participants' motivation to take an active role in their own and their peers' meaning-making processes (Whiteside, 2007, 2011, 2015, 2017). Figure 1 illustrates the Social Presence Model and its five components.

\section{Figure 1}

Social Presence Model

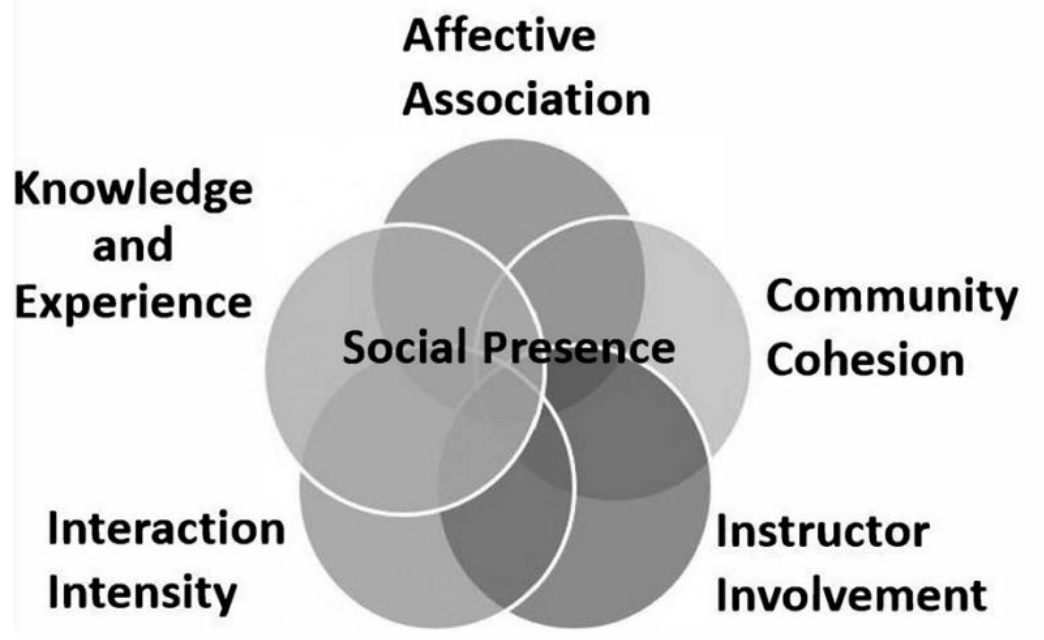

Table 1 defines each of the elements of the SPM: Affective Association, Community Cohesion, Instructor Involvement, Interaction Intensity, and Knowledge and Experience. 


\section{Table 1}

Definitions of Social Presence Model Elements

\begin{tabular}{ll}
\hline SPM Element & Definition \\
\hline Affective Association & $\begin{array}{l}\text { The Affective Association category addresses the } \\
\text { emotional connection, including instances of emotion } \\
\text { (e.g., sadness, anger, frustration, regret, and joy), } \\
\text { humor, and personal self-disclosure. } \\
\text { Community Cohesion relates to the whole course } \\
\text { community. It involves greetings, sharing resources } \\
\text { and information with the group, and seeing the group } \\
\text { as a cohesive whole (e.g., we or our). } \\
\text { Instructor Involvement encompasses the actions the } \\
\text { instructors take within a learning environment and } \\
\text { how students react to them. } \\
\text { Interaction Intensity consists of the level of } \\
\text { interaction among students and instructors. } \\
\text { Knowledge and Experience primarily involves the } \\
\text { knowledge and prior experiences a student brings into } \\
\text { the learning environment and what they share from } \\
\text { those experiences. }\end{array}$ \\
Interaction Intensity &
\end{tabular}

The SPM intends to highlight the critical importance of connections within teaching and learning in different modalities and how cultivating relationships in learning communities can increase student motivation, participation, and learning outcomes. This model can serve as a heuristic for students and instructors who are teaching and learning remotely as well as for those supporting them, including instructional designers, information technologists, and academic leaders (Garrett Dikkers, Whiteside, \& Lewis, 2017; Garrett Dikkers, Whiteside, \& Tapp, 2017; Whiteside, 2007, 2015, 2017; Whiteside, Garrett Dikkers, Lewis, 2017; Whiteside, Garrett Dikkers, \& Swan, 2017). The five elements of the SPM contribute to developing a connected and engaged classroom community, which may also provide indications on how to encourage faculty-student connections in times of emergencies like the COVID-19 pandemic. Our study sheds light on the importance of considering the SPM elements to improve connections during crises.

\section{Methods}

This study employed a quantitative and qualitative single-case design approach to examine students' experience at a mid-sized, private university in the southeastern region of the United States in the transition to remote emergency learning in March 2020. This institution prides itself on quality face-to-face teaching, with just under 10,000 students enrolled in over 200 undergraduate and graduate programs. Before the pandemic, instruction at this school was primarily face-to-face with a small percentage of highly vetted, peer-reviewed online and blended learning courses (included in this study).

Survey and Dyadic Interviews Data Collection

Researchers used a quantitative and qualitative approach to triangulate the data from multiple perspectives to gain more insight into a complex real-world phenomenon, as suggested by the literature (Creswell, 2014). Since the literature points to survey methods to offer the quickest response rate and cost-effective advantages for mid-to-large-sized populations (Babbie, 1973; Fowler, 2009; Creswell, 2014), a mix of closed-choice and open-ended questions focused on the guiding questions. As an interdisciplinary team of researchers, we developed questions 
encompassing demographics consistent with the university standard categories, health and wellness, remote transition experience, and technology. The questions were then distributed to the university committee that reviews and evaluates all online and hybrid courses and revised based upon consensus agreement (Creswell, 2014). The survey included a combination of seven multiple-choice demographic questions, Likert-scale and open-ended questions in each consecutive section, and matrices in the technology section. Additionally, we offered a question at the end of the survey to ask students to volunteer if they were interested in participating in an interview or focus group session elaborating about their experience. The survey was housed in the Qualtrics platform and tested by three students and faculty who provided comments for improvement. After making revisions, the Dean of Students delivered a link to all university students through a global campus email on May 7, 2020 and sent a follow-up email on May 13, 2020. The survey is available upon request.

Additionally, out of six consenting volunteers, two accepted to participate in an interview held in July 2020, and two accepted to participate in an interview held in August $2020(\mathrm{n}=4)$.

Two semi-structured dyadic interviews were conducted to triangulate the data. Dyadic interviews offer a small comfortable environment for participants to build from each other's thoughts, creating a conversational transaction (Morgan, et al., 2013; Morgan, et al., 2016). A semistructured protocol was used with questions taken from the original survey as a guide to prompt discourse by and between the interviewees. Questions used were discussed and selected through a consensus agreement of all four researchers. The dyadic interviews were completed in a webinar room, and participants were allowed to change their profile names and keep their videos off. Two researchers conducted the interviews while rotating questions. All four interviewees kept their videos on and appeared eager to share their experiences.

\section{Data Analysis}

This study analyzes and synthesizes data to understand more about the specific experiences of students during the pandemic situation framed with the SPM. Using a transformative explanatory sequential approach (Hodgkin, 2008; Creswell, 2014) to analyze the data exported from Qualtrics, researchers initially reviewed and cleaned the total participants who agreed to participate $(n=711)$. Researchers quantitatively analyzed results by running descriptive and inferential statistical tests through SPSS and qualitatively coded the open-ended questions and dyadic interview transcripts using ATLAS.ti (Strauss \& Corbin, 1990) to encase the study with the SPM codes. The categorization for qualitative coding data was derived deductively using all five themes or elements of the SPM (affective association, community cohesion, instructor involvement, interaction intensity, and knowledge and experience).

\section{Quantitative Analysis}

Beginning with the 711 students who participated in the survey from a total of approximately 9600 (7\% response rate), the lead researcher reviewed the data for large gaps in responses to reduce the potential of bias. Through a series of discussions and consensus agreements (Creswell, 2014), the four researchers removed several incomplete records from the data; 47 completely blank records; 31 records that only completed the demographic section; 51 records that were completed through the health section; 31 that were completed through the remote experience section; and 44 records that stopped before the technology matrices that decreased the total number to 507 participants who completed $50 \%$ or more of all sections on the survey. The final number of 507 respondents is a representative sample to get statistically significant results using a confidence level of $95 \%$ and a margin error of 5\%. Excluding data 
pools provided a specific focus of this study to use a complete data set of those engaged in all survey parts leveraging the SPM as a guiding framework.

The researchers ran one-way analysis of variance (ANOVA) tests to compare the means of multiple variables and determine if any statistically significant differences existed between the means of three or more independent groups. Upon finding statistical significance, Levene's Homogeneity of Variance tests were run to determine variances. If the test passed as not significantly variant, post hoc tests were then run to confirm or reject statistical significance (Green \& Salkind, 2005).

\section{Qualitative Analysis and Coding}

To understand students' emotional needs during emergency remote learning based on the SPM, data analysis focused on coding for the five elements of the Social Presence Model: Affective Association, Community Cohesion, Instructor Involvement, Interaction Intensity, and Knowledge and Experience in a qualitative tool called ATLAS.ti 9. Three artifacts were coded: open-ended survey results for challenges, open-ended survey results for instructional strategies, and two dyadic interviews transcripts. Two researchers coded approximately $30 \%$ of the data with interrater reliability of $83.33 \%$. Researchers also met on multiple occasions to address the coding and resolve questions through consensus agreement. The categories coded were not mutually exclusive. Table 2 lists examples of these codes.

\section{Table 2}

\section{Sample Coding}

Student Open-Ended Responses
I liked when professors uploaded PowerPoints to blackboard
My teacher also used Canvas to post PowerPoints during every class instead
of teaching them live. It was easier for me to learn with those PowerPoints.
Zoom really gave me a headache.

Having all of us use zoom and requiring that we share video to have us all be engaged.

My teacher made a podcast and she made power-points with voiceover. Having open office hours to clarify assignments with the teacher. open hours on zoom and being able to talk to the instructor instead of waiting for them to email you back

\section{Codes}

Affective Association, Instructor Involvement

Instructor Involvement, Knowledge and Experience, Affective Association, Interaction Intensity

Interaction Intensity

Instructor Involvement Instructor Involvement Instructor Involvement

The researchers acknowledge important limitations of the data. To complete a large questionnaire during a pandemic may have been a daunting task for participants. The 204 respondents eliminated due to incomplete sections may offer valuable information in their responses but could not be generalized. Likewise, students experiencing the greatest challenges with technology and internet connectivity may not have contributed valuable perspectives to this study without the necessary electronic access. The number of qualitative interviews conducted in comparison to survey responses is also low. Due to this study occurring during a pandemic, students were challenged to participate in an interview but seemed to want to share their experiences through the survey.

Furthermore, reporting the results from instruments administered during the initial onslaught of the emergency might reflect different views of students' experiences than from a longitudinal study given more time to cope with learning through a pandemic. It is also important 
to highlight that this paper does not include the faculty perspective during COVID-19 emergency remote learning. Faculty results are part of the future reports of our extensive study in instructorstudent connections in times of crisis. The authors also acknowledge the short-term nature of the data (e.g., student remote learning experiences from March to May 2020). This limitation suggests avenues for future studies. Finally, the researchers recognize that the unique characteristics of this higher ed private university with a history of the face-to-face student population are not generalizable to all schools.

\section{Student Demographics}

\section{Results}

Overall, demographics of respondents included a broad range of students across all four colleges at the university, with 33\% from the College of Business, 33\% from the College of Natural and Health Sciences, 18\% from the College of Arts and Letters, 16\% from the College of Social Sciences, Mathematics, and Education. Gender encompassed 74\% female, 25\% male, $1 \%$ non-binary. Categorizing participants' ages into generations (Dimock, 2019), student ages fell primarily within $88 \%$ of $\mathrm{Z}$ generation (1995 - 2010, with the lowest age in this higher educational institution being 17 to 25 -year-olds), 9\% of Y generation (1980 - 1994, 26 to 40year-olds), and 3\% of X generation (1960 - 1979, 41 to 60-year-olds). Table 3 provides the demographic descriptors of the study.

\section{Table 3}

Demographic Descriptors of the Study

\begin{tabular}{|c|c|c|c|c|c|}
\hline Ethnicity & $\begin{array}{l}72 \% \text { White, non- } \\
\text { Hispanic }\end{array}$ & $\begin{array}{l}12 \% \\
\text { Hispanic/Latino }\end{array}$ & $\begin{array}{l}5 \% \text { Black or } \\
\text { African American, } \\
\text { non-Hispanic }\end{array}$ & $\begin{array}{l}4 \% \text { Asian, non- } \\
\text { Hispanic }\end{array}$ & $\begin{array}{l}4 \% \text { two } \\
\text { or more } \\
\text { races }\end{array}$ \\
\hline Gender & $74 \%$ Female & $25 \%$ Male & $1 \%$ non-binary & & \\
\hline Age & $\begin{array}{l}88 \% 17-25 \\
\text { years old }\end{array}$ & $\begin{array}{l}9 \% 26-40 \\
\text { years old }\end{array}$ & $\begin{array}{l}3 \% 41-60 \\
\text { years old }\end{array}$ & & \\
\hline Classification & $\begin{array}{l}26 \% \\
\text { Junior }\end{array}$ & $\begin{array}{l}22 \% \\
\text { Freshmen }\end{array}$ & $\begin{array}{l}21 \% \\
\text { Senior }\end{array}$ & $\begin{array}{l}17 \% \\
\text { Sophomore }\end{array}$ & $\begin{array}{l}15 \% \\
\text { Graduate }\end{array}$ \\
\hline Discipline & $33 \%$ Business & $\begin{array}{l}33 \% \text { Natural and } \\
\text { Health Sciences }\end{array}$ & $\begin{array}{l}18 \% \text { Arts and } \\
\text { Letters }\end{array}$ & $\begin{array}{l}16 \% \text { Social } \\
\text { Science, Math, } \\
\text { and Ed }\end{array}$ & \\
\hline $\begin{array}{l}\text { Prior } \\
\text { online/hybrid } \\
\text { courses }\end{array}$ & $\begin{array}{l}83 \% \\
\text { None or }<1 \text { year }\end{array}$ & $\begin{array}{l}15 \% \\
1-3 \text { years }\end{array}$ & $\begin{array}{l}3 \% \\
4+\text { years }\end{array}$ & & \\
\hline
\end{tabular}

Ethnicities included 72\% White/non-Hispanic, 12\% Hispanic/Latino, 5\% Black or African American/non-Hispanic, 4\% Asian/non-Hispanic, 4\% two or more races, non-Hispanic, $3 \%$ two or more races including Hispanic, $1 \%$ other. Regarding classification, respondents were $26 \%$ juniors, $22 \%$ freshmen, $21 \%$ seniors, $17 \%$ sophomores, and $15 \%$ graduates. Students' years of online or hybrid classes reflected the teaching methodology offered at the university before COVID, with $83 \%$ having less than one year experience, $15 \%$ one to three years of experience, $3 \%$ four-plus years. Respondent demographics align with the overall student population at the 
university. Respondents were overwhelmingly female; however, this matches the institution demographics for 2019-2020, with the university's overall undergraduate population as $60 \%$ female and $40 \%$ male. Additionally, Table 3 reflects that $86 \%$ of the respondents were undergraduate, which aligns with the university demographics of $90 \%$ undergraduate.

\section{Remote Learning Experience: Overall}

ANOVA test results, confirmed with post hoc tests, found statistical significance when Classification and Years of Online Class Experience factors were compared to Remote learning worked well for me. This variable used a five-star scale, where students were asked to rate their experience. Within the Classification factor, statistical significance was reflected between the graduate to freshmen groups, with first-year students averaging closer to two stars and graduate students averaging over three stars. The data also reflects a steady incline in the mean as the education classification increased. The statistics are reported in Tables 4 and 5.

Table 4

\begin{tabular}{lrrrr}
\multicolumn{5}{l}{ Classification: Remote Learning } \\
\hline Classification & N & \multicolumn{1}{l}{ Mean } & Valid Percent & Std. Dev. \\
\hline Freshmen & 95 & 2.42 & $21.9 \%$ & 1.334 \\
Sophomore & 79 & 2.53 & $17.1 \%$ & 1.279 \\
Junior & 117 & 2.57 & $25.7 \%$ & 1.289 \\
Senior & 99 & 2.66 & $20.5 \%$ & 1.268 \\
Graduate & 70 & 3.10 & $14.9 \%$ & 1.543 \\
\hline Total & 460 & 2.64 & $100.0 \%$ & 1.345 \\
\hline
\end{tabular}

Table 5

Multiple Comparisons: Tukey HSD post hoc Test Results

\begin{tabular}{llrrr}
\hline Classification A & \multicolumn{1}{c}{ Classification B } & Mean Difference (A-B) & Std. Error. & Sig. \\
\hline Freshmen & Graduate & -.679 & .210 & $.011^{*}$ \\
& Senior & -.256 & .192 & .670 \\
& Junior & -.152 & .184 & .923 \\
& Sophomore & -.111 & .203 & .963 \\
\hline
\end{tabular}

Note: $*$ The mean difference is significant at the 0.05 level.

Regarding the Years of Online/Hybrid Class Experience factor, the researchers reached a consensus agreement to merge the one outlier in the six to seven years of experience group with the population of four to five years of experience for a variable of four-plus years. ANOVA factorial results and confirmatory post hoc tests reflected statistical significance for those with less than one year compared with those in the one-to-three years group when run against the Remote learning worked well for me variable as displayed in Tables 6 and 7. On average, students with less than one year of experience with online or hybrid learning highlighted less than three stars that remote learning worked well for them. Students having one or more years of experience highlighted more than three stars. 
Table 6

Online Experience Descriptive Statistics: Remote Learning Worked Well-Highlight Stars to Rate Agreement

\begin{tabular}{lrrrr}
\hline Years of Online Experience & \multicolumn{1}{c}{$\mathrm{N}$} & Mean & Valid Percent & Std. Dev. \\
\hline$<1$ & 375 & 2.51 & $82.4 \%$ & 1.304 \\
$1-3$ & 67 & 3.28 & $14.7 \%$ & 1.444 \\
$4+$ & 13 & 3.08 & $2.9 \%$ & 1.256 \\
\hline Total & 455 & 2.94 & $100.0 \%$ & 1.351 \\
\hline
\end{tabular}

Table 7

Multiple Comparisons: Tukey HSD post hoc Test Results

Years of Online Experience A Years of Online Experience B $\quad$ Mean Difference (A- $\quad$ Std. Error. $\quad$ Sig.

B)

\begin{tabular}{rlrrr}
\hline$\leq 1$ & $1-3$ & -.774 & .176 & $.000^{*}$ \\
\hline & $4+$ & -.568 & .374 & .283 \\
\hline
\end{tabular}

Note: * The mean difference is significant at the 0.05 level.

Researchers observed that the recurring theme of an investment of time in online courses improved the experience, which was also supported by qualitative responses. One student reflected, "Time improved the experience and use of technologies; students and teachers learning together became a more self-driven [conscious] effort; self-reflections improved learning experience."

\section{Remote Learning Experience: Findings from the SPM}

The Social Presence Model coding revealed findings of the student remote learning experience through the three coded artifacts: (a) open-ended survey results for challenges, (b) open-ended survey results for instructional strategies, and (c) dyadic interview transcripts. The results in this section, using deductive reasoning, identify themes about the student experience within the five elements of the Social Presence Model: Affective Association, Community Cohesion, Instructor Involvement, Interaction Intensity, and Knowledge and Experience which are explained and defined in this section. The coding yielded 305 SPM codes across the three artifacts using the qualitative coding software ATLAS.ti 9. Figure 2 illustrates the coding breakdown for the frequency of each element of the SPM. 


\section{Figure 2}

SPM Codes on Student Remote Experiences (Frequencies)

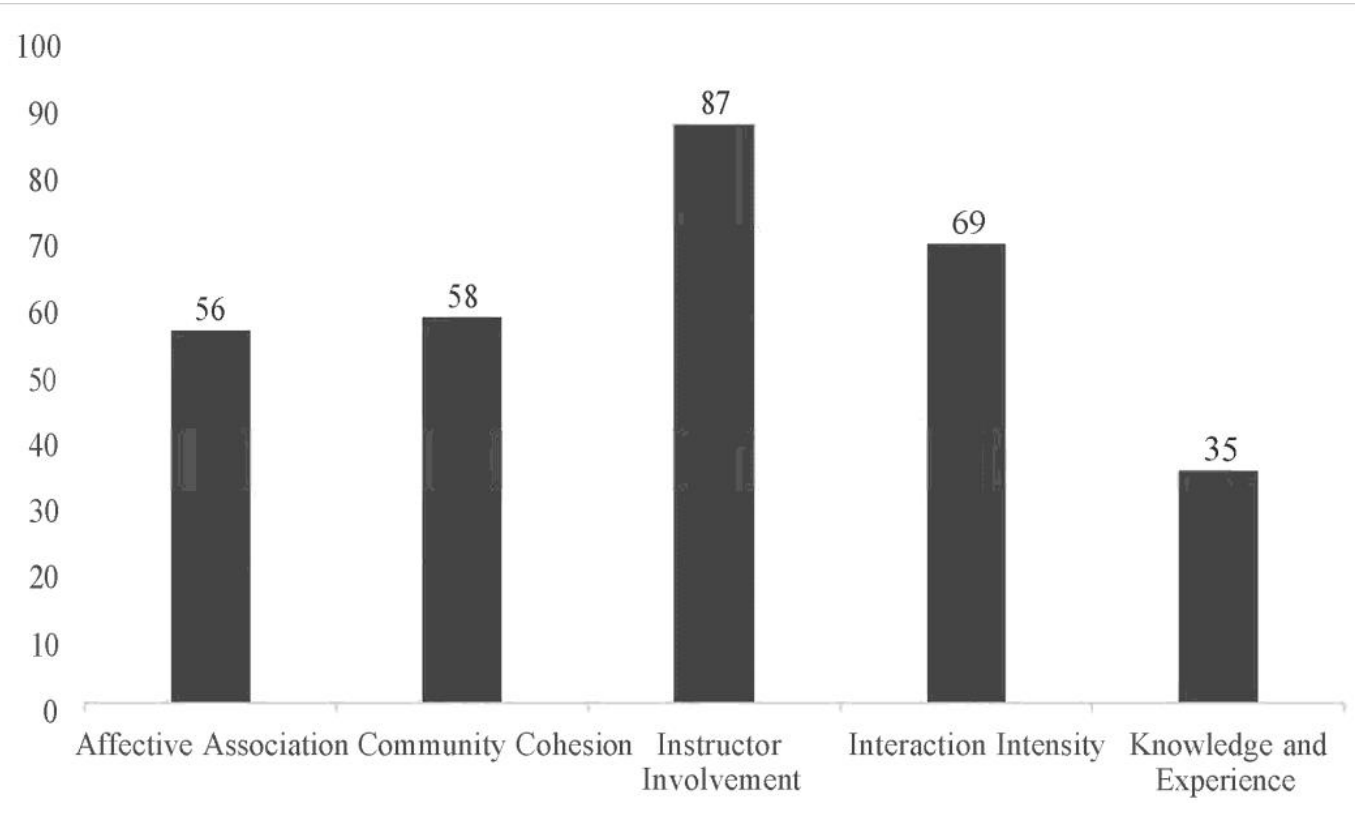

Each code revealed a pattern of responses about students' emergency remote learning experience. The subsections — one for each of the elements of the SPM—provide further detail about those patterns and responses.

\section{Affective Association}

The Affective Association code addresses the students' emotions in the remote learning situation. Researchers coded feelings of concern, sadness, anger, frustration, regret, joy, and elation in this area. Students' responses featured three main themes: (a) loneliness/isolation, b) anxiety/depression, and c) stress. Students addressed how the pandemic affected them. One student addressed the challenges as "loneliness, lack of motivation and a lot of mixed emotions." Another student elaborated a bit further:

The whole thing was a shock that I couldn't have prepared myself for. I went home for spring break thinking I'd be here for a week and learned I'd be home for 6 months. Transitioning to online school was very hard for me because it's not how I like to learn.

Likewise, several students commented about "not having a schedule" and felt as though they were "in this all by" themselves.

Feeling stressed emerged often for student respondents. One student offered a lot of emotion about the pandemic in a very emotionally charged answer: "Adapting to a completely new system of learning, coping with professors' confusion, stress from being socially isolated, stress from an international pandemic occurring that is killing thousands EVERY DAY." Another student addressed the stress of "managing the changing expectations of 5-7 instructors who were also learning-on-the-fly." Not only were students coping with multiple professors handling remote learning in different ways, but many reported unreliable or no Internet connection, which intensified their stress. One student explained, "During this transition, it was challenging to have unreliable Internet services at home. As all my classes depended on 
Blackboard, Zoom, and other mediums, it was unbelievably stressful to have to do it all with spotty Internet." If those factors were not enough, many students commented on the stress of moving back in with their families. One student explained,

Of course, my family was a huge distraction that made concentrating on work a million times harder. It was stressful being home when my relationship with my family is not the best. I missed.... campus for the freedom, flexibility, and opportunities it provides in comparison with remote learning.

Unsurprisingly, numerous students reported missing peer connections and facing anxiety and depression, resulting in loneliness and stress. One explained, "Graduation was cancelled, my senior year ended before it began, I have anxiety/insomnia and I'm prone to depression, all of which came back in full force." One student noted the overwhelming financial worries that rendered school less important. This student commented, "feeling alone, defeated, anxious. School was not my number one priority as I was worried about unemployment, paying my bills, and the safety of my family."

\section{Community Cohesion}

The Community Cohesion code relates to the level of interconnectedness of the course community. Students' responses (58) in this area fell, for the most part, into three main themes: (a) inauthenticity and awkwardness of remote classes, b) missing peers, and c) feeling disconnected.

One common theme that respondents mentioned was the inauthenticity and awkwardness of discussions in the remote learning courses. One student commented about the challenge of "not seeing people face-to-face and the awkwardness of online conversation." Similarly, another student noted their "boredom" and the "forced interaction that did not feel organic in classes." A final student was more candid about the loss of community: They noted, "logging into zoom meeting every time sucked, no one paid attention in classes."

Underlying the inauthenticity noted were many students lamenting missing friends, which amounted to about half of the 58 codes in this area. One student commented, "not seeing my peers, having trouble with motivation, depression." Several students longed for "the classroom situation" or the "lack of the educational social experience." Though most students reported on challenges with remote learning, one proactive student reported "doing homework with my roommate" as a coping strategy.

Along with missing friends, students overwhelmingly noted a feeling of disconnectedness from their course community. One student commented about the strain of "staying in one place to do my learning, lack of face-to-face interaction, lack of motivation, and inability to gather with friends." Numerous students pointed to feeling lost and "disconnected from school" due to other priorities with the pandemic situation.

\section{Instructor Involvement (Student Perceptions)}

The most heavily coded element of the Social Presence Model was Instructor Involvement, which relates to the instructors' actions within a learning environment and how students react to them. The 87 codes for this category are separated into three main areas: empathy, planning, and flexibility.

In terms of empathy, student respondents noted the amount of care on the part of instructors. One commented about "two professors who really showed they care about us and our well-being." Students commented on how caring professors distracted them from the pandemic 
with office hours and trying to create a new "normal" while they could be "mentally engaged." Students appreciated and equated accommodations made for them outside the structured class with being cared about. One student wrote, "Teachers were accommodating, despite a dreadful situation."

While professors may offer a range of office hours on Zoom to support international students and students in other time zones, some students viewed this as inconsistent and having "office hours at random times throughout the day." Students also mentioned several instances of professors not communicating fast enough and equated that with a lack of care, concern, and empathy. One student noted needing much less from the university and much more care and communication from her instructors: "Lack of communication with professors and an OBNOXIOUS amount of spam from the school." Interestingly, some students equated the instructors that did synchronous learning, or what they called "screen sharing through Zoom," and who had "built-in office hours" as "when the professor actually cared." On the other hand, asynchronous instruction was often described as "just professors assigning work" or an "academic farce."

In terms of planning, another key theme, students noted that successful professors used "effective communication through email and [followed] a revised schedule." Another agreed, noting, "One of my teachers took the time to lay out her strategy for the rest of the semester so that we would know what to expect. The same teacher also made it clear that she was open to questions, encouraging us to ask about it if we didn't understand something." Students seemed to point to instructor planning and preparation as equating to caring for them and their well-being, as time management and scheduling were frequently mentioned as a challenge.

Finally, flexibility also emerged as a key consideration among students. One student noted the importance of "extra flexibility" from professors because "technology doesn't always work well." Another student noted, "All of my professors were understanding, compassionate, and flexible during this transition, which is very much appreciated."

\section{Interaction Intensity}

In the Social Presence Model, the Interaction Intensity code consists of the level of interaction among students and instructors. This code emerged in 69 codes in this study, mainly as a lack of interaction or a severe need for it. Two themes emerged: human interaction and engagement.

The theme of lack of human interaction came up frequently in the emergency remote learning experience. In a question about the challenges they faced, student respondents often commented on "being alone with little human interaction" or "lack of face to face interaction" or "lack of social interaction." Many students connected this lack of interaction to learning. One student noted, "not learning anything, little real interaction, hard to retain any information when online." Another student commented that "staying in one place to do my learning" was difficult and not as fruitful.

Other students missed the debates among friends, noting "lack on [sic] interaction and spirited conversations" and the "inability to gather with friends." The final connection students noted was the lack of interaction and the long hours on the screen. One student explained, "The transition to constantly being in front of a computer screen and typing so much more was the biggest struggle. I often don't want to zoom with family or friends or look at social media after being in front of the computer for work and school." So, for this student, the lack of human interaction was a problem for learning, but Zoom fatigue also affected her personal life. 
Additionally, students commented on finding newfound engagement and interactions with professors. One student noted, "Zoom was good for engaging (depends on professor personality)." Another student agreed, suggesting "teachers that [sic] took the extra step to engage with the class" were "there for their students if they ever needed it." Additionally, students noted the use of video to engage, interact, and connect with the whole course community. In a question about instructor strategies, one student noted, "Being required to have videos on and being required to participate made my classes more enjoyable and felt more regular. Classes that didn't require that or didn't allow that were very hard to sit through." Overall, several students noted positive interactions with their professors via various web conferencing and messaging tools.

\section{Knowledge and Experience}

The Knowledge and Experience code traditionally refers to the knowledge and prior experiences students bring into the learning environment and what they share from those experiences. This study also referred to the overall learning experience. While this code appeared less often than the other codes, two themes emerged from the 35 codes: lack of support and an unmotivating experience.

The data showed multiple instances of lack of support for moving forward with their studies and knowledge. In answering a question about effective instructor strategies, one student noted that effective instruction involved "communication with students, answer[ing] all queries, and support[ing] students throughout remote classes." Many students noted being unsupported to learn and retain the material in the emergency remote learning situation. One noted, "Teaching myself, no support, etc. here." Another agreed, suggesting "basically having to teach myself everything." Another student commented, "not learning anything, little real interaction, hard to retain any information when online." The data also suggested that some students perceived professors who didn't use synchronous technology as not supporting them. One student explained, "It [not using Zoom] really made me feel like my professors did not support me and had no interest in my success."

Finally, student respondents often addressed how they were not getting the face-to-face, hands-on experience for which they paid. One student explained, "I didn't want to go to class or study. I was very unmotivated. It's hard to learn as a marine bio major online. I'm not getting the hands-on expirence [sic]." Another student agreed, suggesting they were "[f]eeling disconnected from school and unmotivated." This student continued to explain, "Work didn't feel important and therefore it was harder to do. Without the school environment I really lost touch. I'm normally a good student and I found it really hard to teach myself and continue to learn." Many other students felt they deserve a refund from the university. One student explained, "I don't think the professors could have done any better, considering they were given as much assistance as the students with the online transition. They should all get bonuses, and we should get refunds."

\section{Discussion}

\section{RQ1. What was the student experience in the transition to remote learning?}

It was overwhelming for undergraduate students to balance a pandemic, travel, move, and shift academic expectations. Statistically, we uncovered that our first-year college students struggled the most, and graduate students had an easier transition. Many of our first-year students noted that it was a difficult transition for them, while graduate students recognized the flexibility 
and possibilities. One graduate student noted, "[The university] should use this opportunity to expand their curriculum to include online learning to reach more potential students."

Students addressed how the gravity of the pandemic situation affected their mental health, which also impacted their ability to learn. Many of them reported feeling "in a really dark place." Several reported that they were shocked and overwhelmed by the global public pandemic. As a result, students noted feeling lonely and stressed as well as missing peer connections and facing mild to severe anxiety and depression.

Likewise, the data suggests that more online preparedness (Abdous, 2019; Cutri et al., 2020) with planned instructor professional development and student orientations for online learning would have helped students transition more smoothly. The university in this study offers predominantly face-to-face courses and, as a result, attracts students who have less online experience. This fact was reflected in the results with most students (407) reporting that they had less than one year of experience with online classes. These results align with the quantitative data results since most students $(83 \%)$ had none or less than a year of previous online/hybrid course experience. The Knowledge and Experience in the SPM was also the lowest element found in the qualitative data coded, showing a lack of prior online experiences among students. This indicates that students did not have adequate knowledge and prior experience in managing online coursework and what it involves. Still, students reported more time and years of online experience worked better during the emergency remote learning. One student suggested,

So I guess the problem was more in the beginning in terms of preparation, like in the beginning, those professors that had to give classes at that specific period of time had the most challenge from my experience. But later on, it started to become more smooth. And I guess now in the fall, it might even get, um, easier or fully smooth. I might say that [worked] the most [smooth]

\section{RQ2. What lessons can we learn moving forward to better prepare for future public emergencies using the SPM as the guiding framework?}

The main lesson learned from the SPM is the importance of social presence as a literacy. The data revealed the depth of anxiety felt by students and that they needed far more empathy, communication, and flexibility from their instructors to even proceed with academic coursework. The Affective Association SPM codes suggested that students were lonely, anxious, and stressed. Time provided to improve preparedness eases these tensions and fears (Abdous, 2019). The Knowledge and Experience and Instructor Involvement SPM codes unveiled that the students needed empathy, planning, flexibility, support, and motivation to learn. The scope of our study was not to propose a modified SPM for emergency remote learning. Instead, our purpose was to uncover the usefulness of SPM as a guiding framework for remote learning in times of crisis to reduce student stress, anxiety, and lack of motivation.

Students reported benefitting more when instructors' instructional activities involve connecting to them personally (Garrett Dikkers, Whiteside, \& Lewis, 2017; Garrett Dikkers, Whiteside, \& Tapp, 2017; Whiteside, 2007, 2015, 2017; Whiteside, Garrett Dikkers, Lewis, 2017; Whiteside, Garrett Dikkers, \& Swan, 2017), such as referring to them by name and incorporating pandemic icebreakers and interaction. The Interaction Intensity SPM code unveiled the need for human interaction and engagement from this study. The younger students equated synchronous learning with caring about their well-being, while strategies like videos can personalize the experience (Conklin \& Garrett Dikkers, 2021). 
During future remote learning emergencies, the elements of SPM should be considered to encourage empathy, interaction, and engagement with students for promoting a cohesive course community.

\section{Conclusion}

Universities must carefully consider the implications this study offers to plan for future unanticipated emergencies proactively (e.g., public health crises and disasters). One simple solution is to educate professors and academic leaders about the importance of social presence as a literacy for learning (Whiteside, 2017). Larger, more complex considerations involve how to support the mental health of our students at a distance. Unless students have their basic needs met, they cannot focus on learning the course content.

It is recommended that universities provide training and professional development opportunities that consider SPM elements in remote learning scenarios to improve facultystudent connection and engagement. This study recommends future exploration based on the Community Cohesion SPM data that revealed students' feelings of inauthenticity, missing peers, and disconnectedness.

Moreover, students who come into the college having more experience online may be better prepared for emergencies. For example, Florida statute 1003.428 specifies that students must complete at least one course through online learning to achieve a high school diploma (The 2020 Florida Statutes). Findings from this study suggest that students entering college might be better prepared if they have more than one online learning experience. One student detailed this in their survey response: "Their state education system requires some students to take 1 online class before graduation... I think it should be more like 1/year. At the college level, many general education courses could be delivered asynchronously."

Ultimately, universities need to prepare all faculty and students in various forms of online learning to foster interconnectedness and allow faculty to help students to weather the transition more successfully during future emergencies. 


\section{References}

Abdous, M. H. (2019). Influence of satisfaction and preparedness on online students' feelings of anxiety. The Internet and Higher Education, 41, 34-44.

Anderson, T., Rourke, L., Garrison, D. R., \& Archer, W. (2001). Assessing teaching presence in a computer conferencing context. Journal of Asynchronous Learning Networks, 5(2), 1-17. https://doi.org/10.24059/olj.v5i2.1875

Babbie, E. (1973). Survey research methods. Wadsworth.

Bird, K., Castleman, B. L., \& Lohner, G. (2020). Negative impacts from the shift to online learning during the COVID-19 crisis: evidence from a statewide community college system. https://www.edworkingpapers.com/ai20-299

Chiu, T. K. F. (2021). Applying the self-determination theory (SDT) to explain student engagement in online learning during the COVID-19 pandemic. Journal of Research on Technology in Education. https://doi.org/10.1080/15391523.2021.1891998

Conrad, R. M. \& Donaldson, J. A. (2012). Continuing to engage the online learner: more activities and resources for creative instruction. San Francisco: Jossey-Bass.

Conklin, S., \& Garrett Dikkers, A. (2021). Instructor social presence and connectedness in a quick shift from face-to-face to online instruction. Online Learning Journal, 25(1). https://doi.org/10.24059/olj.v25i1.2482

Creswell, J. W. (2014). Research design: Qualitative, quantitative, and mixed methods approaches. Sage.

Cutri, R. M., Mena, J., \& Whiting, F. (2020). Faculty readiness for online crisis teaching: transitioning to online teaching during the COVID-19 pandemic, European Journal of Teacher Education, 43(4), 523-541. https://doi.org/10.1080/02619768.2020.1815702

Dimock, M. (2019). Defining generations: Where Millennials end and Generation Z begins. Pew Research Center, 17(1), 1-7.

Ensmann, S. Y., Gomez-Vasquez, L., Sturgill, R., \& Whiteside, A. L. (2021). A pandemic case journal of one higher education institution. Quarterly Review of Distance Education, 21(3), 1923.

Fowler, F. J. (2009). Survey research methods (4th ed.). Thousand Oaks, CA: Sage.

Garrison, D. R. (2007). Online community of inquiry review: Social, cognitive, and teaching presence issues. Journal of Asynchronous Learning Networks. 11.

Garrison, D. R. (2018). Designing a Community of Inquiry. Community of Inquiry. http://www.thecommunityofinquiry.org/editorial9 
Garrison, D.R., Anderson, T., Archer, W. (2010). The first decade of the community of inquiry framework: A retrospective. The Internet and Higher Education. 13(1), 5-9.

Garrett Dikkers, A., Whiteside, A. L., \& Lewis, S. (2017). Blending face-to-face and online instruction to disrupt learning, inspire reflection, and create space for innovation. In A. L. Whiteside, A. Garrett Dikkers, \& K. Swan (Eds.), Social presence in online learning: Multiple perspectives on practice and research. Stylus Publishing.

Garrett Dikkers, A, Whiteside, A. L., \& Tapp, B. (2017). Social presence: Understanding connections among definitions, theory, measurements, and practice. In A. L. Whiteside, A. Garrett Dikkers, \& K. Swan (Eds.) Social presence in online learning: Multiple perspectives on research and practice (pp. 133-142). Stylus Publishing, LLC.

Green, S. B. \& Salkind, N. J. (2005). Using SPSS for Windows and Macintosh: Analyzing and understanding data (4th ed.). New Jersey: Pearson.

Gunawardena, C., \& Zittle, F. (1997). Social presence as a predictor of satisfaction within a computer mediated conferencing environment. American Journal of Distance Education 11(3): $8-26$.

Hodgkin, S. (2008). Telling it all: A story of women's social capital using mixed methods approach. Journal of Mixed Methods Research, 2(3), 296-316.

Lave, J., \& Wenger, E. (1991). Situated learning: Legitimate peripheral participation. New York and Cambridge, UK: Cambridge University Press.

Martin, F., \& Parker, M. A. (2014). Use of synchronous virtual classrooms: Why, who and how? MERLOT Journal of Online Learning and Teaching, 10(2), 192-210.

Martin, F., \& Bolliger, D. U. (2018). Engagement matters: Student perceptions on the importance of engagement strategies in the online learning environment. Online Learning Journal, 22(1), $205-222$.

Martin, F., Stamper, B., \& Flowers, C. (2020). Examining student perception of their readiness for online learning: Importance and confidence. Online Learning Journal, 24(2), 38-58. https://doi.org/10.24059/olj.v24i2.2053

Morgan, D. L., Ataie, J., Carder, P., \& Hoffman, K. (2013). Introducing dyadic interviews as a method for collecting qualitative data. Qualitative Health Research, 23(9), 1276-1284.

Morgan, D. L., Eliot, S., Lowe, R. A., \& Gorman, P. (2016). Dyadic interviews as a tool for qualitative evaluation. American Journal of Evaluation, 37(1), 109-117. 
Nguyen, T., Netto, C. L. M., Wilkins, J. F., Bröker, P., Vargas, E. E., Sealfon, C. D., Puthipiroj, P., Li, K. S., Bowler, J. E., Hinson, H. R., Pujar, M., \& Stein, G. M. (2021). Insights into students' experiences and perceptions of remote learning methods: From the COVID-19 pandemic to best practice for the future. Frontiers in Education, 6, 91. https://www.frontiersin.org/article/10.3389/feduc.2021.647986

Rapanta, C., Botturi, L., Goodyear, P., Guàrdia, L., \& Koole, M. (2020). Online university teaching during and after the Covid-19 crisis: Refocusing teacher presence and learning activity. Postdigital Science and Education Journal 2, 923-945 (2020). https://doi.org/10.1007/s42438020-00155-y

Rutherford, T., Karamarkovich, S., Xu, D., Tate, T., Sato, B., Baker, R., \& Warschauer, M. (2021). Profiles of instructor responses to emergency distance learning. Online Learning, 25(1). https://doi.org/10.24059/olj.v25i1.2472

Short, J., Williams, E., \& Christie, B. (1976). Theoretical approaches to differences between media. The Social Psychology of Telecommunications. London: Pitman Press.

Strauss, A., \& Corbin, J. (1990). Basics of qualitative research. Sage publications.

Swan, K., Garrison, D. R. \& Richardson, J. C. (2009). A constructivist approach to online learning: The Community of Inquiry framework. In C. R. Payne, (Ed.) Information technology and constructivism in higher education: Progressive learning frameworks (pp. 43-57). IGI Global.

Swan, K., \& Shih, L. F. (2005). On the nature and development of social presence in online course discussions. Journal of Asynchronous Learning Networks, 9(3), 115-136. https://doi.org/10.24059/olj.v9i3.1788

Tang, Y. M., Chen, P. C., Law, K. M., Wu, C. H., Lau, Y. Y., Guan, J., He, D., \& Ho, G. T. S. (2021). Comparative analysis of student's live online learning readiness during the coronavirus (COVID-19) pandemic in the higher education sector. Computers \& Education, 168, 1-17.

The 2020 Florida Statutes. (2020). Statutes \& constitution: Online sunshine. http://www.leg.state.fl.us/Statutes/index.cfm?App_mode=Display_Statute\&Search_String=\&UR $\mathrm{L}=1000-1099 / 1003 /$ Sections/1003.4282.html 
Wenger, E. (1998). Communities of practice: Learning, meaning, and identity. Cambridge University Press. https://doi.org/10.1017/CBO9780511803932

Wenger, E. (2000). Communities of practice and social learning systems. Organization, 7(2), 225-246. https://doi.org/10.1177/135050840072002

Whiteside, A. L. (2007). Exploring social presence in communities of practice within a hybrid learning environment: A longitudinal examination of two case studies within the School Technology Leadership graduate-level certificate program (Doctoral dissertation). University of Minnesota, Minneapolis, MN.

Whiteside, A. L. (2011). Integrating the Social Presence Model to maximize blended and online learning experiences: Effective practices. Online Learning Consortium. http://olc.onlinelearningconsortium.org/effective_practices/integrating-social-presence-modelmaximize-blended-and-online-learning-experience

Whiteside, A. L. (2015). Introducing the Social Presence Model to explore online and blended learning experiences. Online Learning Journal, 19(2). https://doi.org/10.24059/olj.v19i2.453

Whiteside, A. L. (2017). Making learning relevant and meaningful: Integrating social presence into faculty professional development programs. In A. L. Whiteside, A. Garrett Dikkers, \& K. Swan (Eds.), Social Presence in Online Learning: Multiple Perspectives on Practice and Research. Stylus Publishing.

Whiteside, A. L. (2017). Understanding social presence as a critical literacy: Introduction to part four. In A. L. Whiteside, A. Garrett Dikkers, \& K. Swan (Eds.) Social presence in online learning: Multiple perspectives on research and practice (pp. 133-142). Stylus Publishing, LLC.

Whiteside, A. L., Garrett Dikkers, A., \& Lewis, S. (2017). Overcoming isolation online: Strategies to enhance social presence in practice. In A. L. Whiteside, A. Garrett Dikkers, \& K. Swan (Eds.) Social presence in online learning: Multiple perspectives on research and practice (pp. 180-187). Stylus Publishing, LLC.

Whiteside, A. L., Garrett Dikkers, A. \& Swan, K. (2017). Social presence in online learning: Multiple perspectives on practice and research. Stylus Publishing.

Zhao, C., \& Kuh, G. (2004). Adding value: Learning communities and student engagement. Research in Higher Education, 45, 115-138. 